\title{
Pattern of Antimicrobial Sensitivity of Organisms Causing Urinary Tract Infection in Nephrotic Syndrome in Children
}

\author{
TANUKA BARUA ${ }^{1}$, SUKHENDU SHEKHAR SEN ${ }^{2}$, JHULAN DAS SHARMA ${ }^{3}$, MAHMOOD AHMED \\ CHOWDHURY ARZU ${ }^{4}$, LUTFANESSA ${ }^{5}$, PRADIP KUMAR DUTTA ${ }^{6}$
}

\begin{abstract}
Background: Urinary tract infection (UTI) is a common infection in nephrotic syndrome children having a propensity for long term renal damage. Organisms causing UTI in nephrotic syndrome are becoming resistant to common antimicrobial agents and increase the morbidity and mortality. Surveillance of local antibiotic sensitivity pattern is necessary for proper management of UTI in nephrotic children.
\end{abstract}

Objective: To see the pattern of antimicrobials sensitivity of organisms causing UTI in Nephrotic syndrome children.

\begin{abstract}
Methods: This was a hospital based cross-sectional study conducted in the department of Paediatrics, Chittagong Medical College Hospital, Chittagong from January 2009 to December 2009. 52 nephrotic children aged 2-6 years with typical clinical features were included. A clean catch midstream urine sample were collected in aseptic procedure and sent for inoculation in culture media. In case of collection failure, urine was collected by sterile catheterization. Bacterial isolates were tested for microbial sensitivity. Data regarding etiological organisms and antibiogram were analyzed using appropriate statistical method.
\end{abstract}

Results: UTI was found in $30.8 \%$ nephrotic children. E-coli was the commonest organism isolated in urine culture followed by klebsiella. All organisms isolated on culture were more or less resistant to commonly used antibiotics except to amikacin. $E$ coli were resistant to most of antibiotics and resistance to cotrimoxazol is quite high for all isolates. Ciprofloxacin as oral and amikacin as parenteral are good for first line treatment of UTI in nephrotic syndrome.

Conclusion: Resistance among organisms causing UTI in nephrotic syndrome is an emergent problem now a day. Routine urine culture should be advised since treatment failure is likely to occur with commonly used antibiotics. Risk factor for emergence of antibiotic resistance of these pathogens should be evaluated.

Key words: Antibiotic sensitivity, Nephrotic syndrome, UTI.

1. Assistant Professor, Department of Pediatrics, Chattagram Maa-O-Shishu Hospital Medical College, Chittagong.

2. Assistant Professor, Department of Pediatrics, Chattagram Maa-O-Shishu Hospital Medical College, Chittagong.

3. Head, Department of Pediatrics, Southern Medical College, Chittagong.

4. Head, Department of Pediatrics, Chattagram Maa Shishu-OGeneral Hospital, Chittagong.

5. Assistant Professor, Department of Pediatrics, Abdul Malek Ukil Medical College, Noakhali.

6. Head, Department of Nephrology, Chittagong Medical College, Chittagong.

Correspondence: Dr. Tanuka Barua, Assistant Professor, Department of Pediatrics, Chattagram Maa-O-Shishu Hospital Medical College, Chittagong. E- mail:tanuka.barua@yahoo.com

\section{Introduction}

Children with nephrotic syndrome are exposed to a variety of infection specially in developing countries like Bangladesh. Urinary tract infections is one of the most common infection in nephrotic syndrome children and may result in delayed steroid response, thereby in prolonged hospital stay and may be a cause of morbidity. ${ }^{1}$

UTI in nephrotic syndrome can be caused by gram negative bacteria such as E coli, Klebsiella species, Enterobactor species, Proteus species and gram positive bacteria such as Enterococcus species, 
Staphylococcus saphrophyticus. ${ }^{1,2}$ Generally, E coli is the most common organism causing both community as well as hospital acquired UTI. ${ }^{3}$ Health care associated UTI (mostly related to urinary catheterization) involve much broader range including E coli $(27 \%)$, Klebsiella (11\%), Pseudomonus(11\%), Enterococcas (7\%), Candida (9\%) and others. ${ }^{4,5,6}$ UTI due to Staphylococcus aureus occur secondary to blood-born infections. ${ }^{7}$

The choice of antibiotic depends on the species and antibiotic sensitivity profiles of the infecting organisms. Local resistance data is important in selecting empirical antibiotic. ${ }^{8}$ Children with uncomplicated UTI can be treated with oral antibiotic such as trimethoprim-sulphamethoxazole, amoxicillinclavulanic acid, 2nd genaration cephalosporin (cefuroxime, cefprozil), $3^{\text {rd }}$ genaration (cefixime, cefpodoxime, ceftibuten, cefdinir), nitrofurantoin and some of the well known parenteral agents like ampicillin and gentamycin for enterococci, Group B streptococcus and gram negative bacteria and third generation cephalosporin (ceftazidime, ceftriaxone, cefepime) are used in resistant uropathogens. ${ }^{9,10}$ If intravenous therapy chosen, single daily dosing of aminoglycosides is safe and effective..$^{11}$ Now a days, flouroquinolones are not recommended as a first line treatment due to emergence of resistance to this class of medication ${ }^{8,12}$ Amoxicillin-clavulanate appears less effective than other options. ${ }^{13}$

The resistance rate of $E$ coli to various antibiotics have been reported as beta-lactum (58.6\%), quinolones $(74.5 \%)$, gentamycin $(58.2 \%)$, amikacin $(33.4 \%)$, cotrimoxazol $(48.5 \%))^{3,14,15,16,17}$ UTI due to multi drug resistance $\mathrm{E}$ coli increase the cost of treatment, morbidity and mortality specially in developing countries. ${ }^{18,19}$

Despite the precaution, some resistance has developed to all of these medications related to their widespread use.$^{20}$ Increasing antibiotic resistance is causing concern about the future of treating UTI in nephrotic syndrome. ${ }^{21,22}$ In nephrotic syndrome, children are prone to recurrent UTI due to decrease immunity, steroid use and disease itself. So there is chance of repeated and widespread use of common conventional antibiotics that may be risk factor for emergence of antibiotic resistance.
Empiric treatment of UTI is determined by the antibiotic sensitivity pattern of uropathogens in a community or in a hospital. There have been very few studies regarding UTI in nephrotic syndrome showing mainly prevalence and etiological spectrum causing UTI in nephrotic syndrome. Information about antibiotic sensitivity pattern of organisms of UTI in nephrotic syndrome is really scarce. We undertook this study to analyze the spectrum of UTI in children with nephrotic syndrome with objectives to identify the etiological organisms causing UTI in nephrotic syndrome and to observe the antibiotic sensitivity pattern of the organisms which will help us to establish local guideline for treatment of UTI in nephrotic syndrome.

\section{Materials and Methods}

It was a cross-sectional study enrolling 52 nephrotic syndrome children. These children were admitted consecutively in Pediatric Ward of Chittagong Medical College Hospital from January, 2009 to December, 2009. Nephrotic syndrome was diagnosed by low serum albumin, high serum cholesterol and significant Protein Creatinine Index ( $>2 \mathrm{mg}$ protein/mg creatinine or $>200 \mathrm{mg}$ protein/mmol creatinine) or 24 hours total urinary protein (>960mg/ m²/day). ${ }^{23,24}$

Nephrotic syndrome children aged 2-6 years presented with typical features were included. Those who were $<2$ years old or $>6$ years old with atypical presentation like hypertension, gross hematuria, with features of complications other than UTI, with $\mathrm{H} / \mathrm{O}$ of taking antibiotic during last 15 days prior to admission ${ }^{25}$ and secondary nephrotic syndrome patients were excluded.

A clean catch of midstream urine specimen was collected from all children in proper aseptic method and sent to laboratory within 1 hour. In case of collection failure, urine was collected by sterile catheterization. The urine samples were inoculated in blood and MacConkey agar media. All plates were inoculated at $35^{\circ} \mathrm{C}-37^{\circ} \mathrm{C}$ and examined for growth and colony count at 24 and 48 hours. Colony counts were done by loop method. Bacterial isolates were tested for microbial sensitivity by disc impregnation method. A positive culture defined as midstream clean voided specimen with isolation of $10^{5}$ or $>10^{5}$ colony forming unit $/ \mathrm{ml}(\mathrm{cfu} / \mathrm{ml})$ of single organism in 
asymptomatic patient and $10^{4} \mathrm{cfu} / \mathrm{ml}$ in symptomatic patient was considered as definite UTI. ${ }^{26}$ In case of urine collection by catheterization, $5110^{4}$ or greater $\mathrm{cfu} / \mathrm{ml}$ of single organism was significant for UTI. ${ }^{27}$ Data regarding etiological organisms and culture sensitivity pattern were recorded in case record form and statistically analyzed. Protocol was ethically reviewed and approved by Ethical Review Committee of Chittagong Medical College.

\section{Result}

The study group consisted of 52 nephrotic syndrome children. A total 16 children were diagnosed as nephrotic syndrome with UTI patients. Thus the prevalence of UTI in this study was $30.8 \%$ (16 out of 52 cases) (Table- 01 )

Causative organisms of UTI isolated in our study were E coli in $50 \%$ (8 out of 16 ), klebsiella in $25 \%$ (4 out of 16 ), coliforms \& proteus in $18.7 \%$ (3 out of 16 ) \& $6.3 \%$ (1 out of 16 ) respectively (Figure- 01 ).

Table-I

Prevalence of UTI among study groups ( $n=52)$

\begin{tabular}{lcc}
\hline Study Groups & Frequency & Percentage (\%) \\
\hline UTI & 16 & 30.8 \\
No UTI & 36 & 69.2 \\
\hline Total & 52 & 100.0 \\
\hline
\end{tabular}

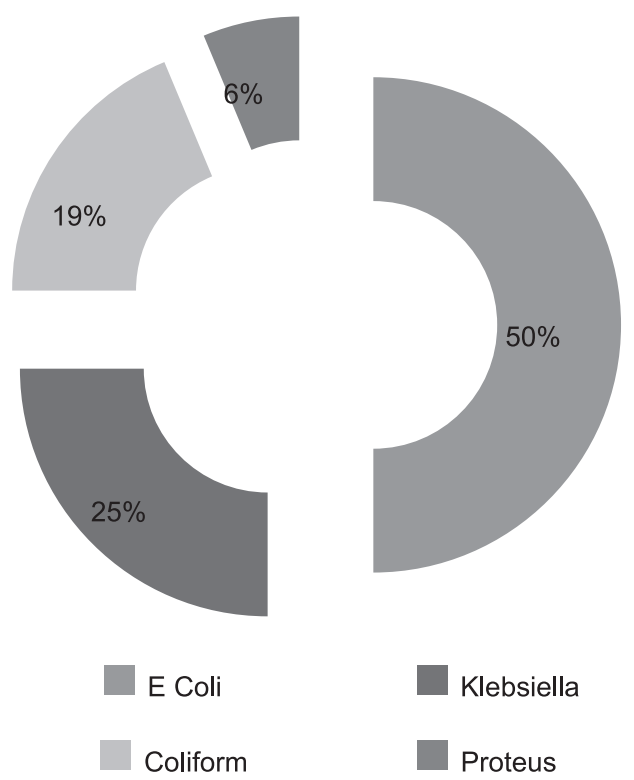

Fig.-1: Organisms isolated in urine culture of nephrotic syndrome

E. coli were sensitive to azithromycin, gentamycin, nitrofurantoin in $62.5 \%$ (5 out of 8 ), to ceftazidime in $50 \%$ (5 out of 4 ), to ciprofloxacin in $37.5 \%$ (3 out of 8 ) but to ceftriaxone in only $12.5 \%$ children (1 out of 8 ). (Table- 02). Klebsiella were sensitive to amikacin, azythromycin, ceftazidime, amoxycillin-clavunalic acid in $100 \%$ cases, to ceftriaxone, ciprofloxacin and nitrofurantoin in $75 \%$ (3 out of 4 ), to cotrimoxazol and gentamycin in $50 \%$ (2 out of 4 ) children. (Table- II).

Table-II

Sensitivity pattern of pathogens isolated from urinary tract of nephrotic patients $(n=16)$

\begin{tabular}{lcccc}
\hline Isolates & E. Coli $(\mathrm{n}=8)$ & Klebsiella $(\mathrm{n}=4)$ & Coliform $(\mathrm{n}=3)$ & Proteus $(\mathrm{n}=1)$ \\
\hline Amoxy-clav & $3(37.5 \%)$ & $4(100 \%)$ & $266.7 \%)$ & - \\
Amikacin & $8(100 \%)$ & $4(100 \%)$ & $3(100 \%)$ & $1(100 \%)$ \\
Azithromycin & $5(62.5 \%)$ & $4(100 \%)$ & $133.3 \%)$ & - \\
Ceftriaxone & $1(12.5 \%)$ & $3(75 \%)$ & $3(100 \%)$ & $1100 \%)$ \\
Ceftazidime & $4(50 \%)$ & $4(100 \%)$ & $3(100) \%$ & - \\
Ciprofloxacin & $3(37.5 \%)$ & $3(75 \%)$ & $3(100 \%)$ & $1100 \%)$ \\
Cotrimoxazole & - & $2(50 \%)$ & $266.7 \%)$ & - \\
Gentamycin & $5(62.5 \%)$ & $2(50 \%)$ & $3(100 \%)$ & $1(100 \%)$ \\
Nitrofurantoin & $5(62.5 \%)$ & $3(75 \%)$ & $3(100 \%)$ & - \\
\hline
\end{tabular}

Amoxy-clav = amoxycillin-clavunalic acid 
Coliforms were sensitive to all antibiotic dices we used in cent percent cases except to amoxycillin-clavunalic acid and cotrimoxazol in $66.7 \%$ (2 out of 3 ) and to azithromycin in $33.3 \%$ ( 1 out of 3 ) cases. Proteus was resistant to most of oral antibiotics including amoxycillin-clavunalic acid, cotrimoxazol, nitrofurantoin, azithromycin, ceftazidime, and was sensitive to only ciprofloxacin, gentamycin, amikacin and ceftriaxone. All four organisms were sensitive to amikacin in hundred percent cases and to ciprofloxacin in more than $70 \%$ cases except $E$ coli that were sensitive to ciprofloxacin only in $37.5 \%$ cases. Amikacin, ceftriaxon and gentamycin and ciprofloxacin were more or less effective in $100 \%$ pathogens. (Table- II).

\section{Discussion}

Prevalence of UTI in nephrotic syndrome was $30.8 \%$ that is consistent with previous studies $13.7 \%$ by Gulati S, Kher V et al, ${ }^{1} 46 \%$ by Ravana K, Sengutthuvan P. ${ }^{28}$ Similar to other studies, ${ }^{1,2}$ the commonest organisms of UTI isolated in this study was $\mathrm{E}$ coli followed by klebsiella. Emila M, Vera H et $\mathrm{al}^{30}$ also found $\mathrm{E}$ coli as the commonest followed by Klebsiella, Enterobactor species, Staphylococcus saprophyticus whereas there was no growth of Enterobactor species or Staphylococcus in this study.

Regarding antibiotic sensitivity test, total 9 antibiotic discs were used named amoxycillin-clavunalic acid, amikacin, azithromycin, ceftriaxone, ceftazidime, ciprofloxacin, cotrimoxazole, gentamycin and nitrofurantoin. Of them, amoxycillin-clavunalic acid, azithromycin, ciprofloxacin, cotrimoxazol and nitrofurantoin are available as oral preparation in our country. E coli were more or less resistant to all the antibiotic discs used. E. coli were sensitive to azithromycin, gentamycin, nitrofurantoin in $62.5 \%$, to ciprofloxacin in $50 \%$, but to ceftriaxone in only $12.5 \%$ children and was resistant to amoxycillin-clavunalic acid in cent percent cases whereas $68.6 \%-86 \% \mathrm{E}$ coli were sensitinve to cotrimoxazol, $80 \%-91.3 \%$ to ciprofloxacin, $84 \%-98.2 \%$ to nitrofurantoin in a study of Mazzalli T. ${ }^{31}$ In other studies, more than $70 \% \mathrm{E}$ coli were resistant to $\mathrm{AMP}^{32}$ and $32.6 \%$ to ciprofloxacin. ${ }^{8}$ In this study Klebsiella were sensitive to amikacin, azythromycin, ceftazidime, amoxycillinclavunalic acid in $100 \%$ cases, to ceftriaxone, ciprofloxacin and nitrofurantoin in $75 \%$, then to cotrimoxazol and gentamycin in $50 \%$ children. But $\mathrm{E}$ coli and klebsiella species showed $78.8 \%$ and $75.3 \%$ resistance to 3 or more drugs respectively in study of Anand kumar H, Kapur I et al. ${ }^{33}$ In this study, Coliforms were sensitive to all antibiotic in cent percent cases except to amoxyclav and to cotrimoxazol in $66.7 \%$ and to azithromycin in $33.3 \%$ cases and in more than $70 \%$ children, both klebsiella and coliforms were sensitive to ciprofloxacin, nitrofurantoin, amoxycillinclavunalic acid and azithromycin that can be given orally. Proteus was resistant to most of oral antibiotics including amoxycillin-clavunalic acid, cotrimoxazol, nitrofurantoin, azithromycin, ceftazidime, and was sensitive to ciprofloxacin, gentamycin, amikacin and ceftriaxone that have to take parenterally except ciprofloxacin. Resistance to cotrimoxazol was significant in all isolates that supported by Mazzalli $\mathrm{T}^{31}$ and Yukseln S, Ozturk B et al. ${ }^{34}$ Emergence of resistance of $E$ coli for both oral and parenteral antibiotics were quite high like other study findings.

Of parenteral drugs, amikacin, ceftriaxone and gentamycin and of oral drugs, only ciprofloxacin were more or less effective in $100 \%$ pathogens. Thus ciprofloxacin was the most active oral drug against majority of uropathogens isolated in this study. This is consistent with the findings of Farrel DG, Monishey I et al. ${ }^{14}$ But nitrofurantoin was the most effective drug showed by some other studies. 8,34,35,36 According to Anand kumar $\mathrm{H}$, Kapur I et al, ${ }^{33}$ cefotaxime appeared to be the highly active against the most prevalent uropathogens. For parenteral route, amikacin was found to be the most active drug against the pathogens isolated in this study. Yuksel S, Ozturk B et $\mathrm{al}^{34}$ and Das M, Padhi S et al ${ }^{36}$ also found amikacin as the most effective drug.

\section{Conclusion}

Children with nephrotic syndrome are frequently predisposed to UTI. E. coli is the commonest organism causing UTI followed by klelbsiella. There is increase of resistance among organisms to majority of commonly used antibiotics. This may be due to prevalence of resistant strains in our community, also may be due to irrational use of antibiotics. Ciprofloxacin appeared as good oral and amikacin as good parenteral drug for treatment of UTI in nephrotic syndrome. Anti-microbial susceptibility testing is crucial for the treatment of UTI in nephrotic syndrome. There should be many more studies regarding antibiotic resistance pattern in locality to develop a guideline for treatment of UTI in nephrotic syndrome and risk factors for emergence of antibiotic resistance should be evaluated in further studies. 


\section{References}

1. Gulati S, Kher V, Arora A, Gupta S, Kale S. Urinary Tract Infection in Nephrotic Syndrome. Pediatr Infect Dis J. 1996;15:237-40.

2. Gulati S, Gupta A, Kher V, Arora P, Rai PK, Sharma RK. Spectrum of Infections in Inadian Children with Nephrotic Syndrome. Pediatr Nephrol. 1995;9:431-34.

3. Sobel D, Kaye D. Urinary Tract Infections. In: Mandell GL, Bennet JE, Dolin R editors. Mandell, Douglas and Bennet's Principles and Practice of Infectious Diseases. $7^{\text {th }}$ ed. Vol 1, Philadelphia, USA: Charchill Livingstone Elsevier Publications 2010.pp 958-72.

4. Chang L, Shortliffe D. Pediatric Urinary Tract Infections. Pediatr Clin North Am. 2006;53:379400.

5. Silvert DM, Ricks P, Edward JR. Anti-microbial Resistance Patterns Associated with Health-care Infections: Summary of Data reported to the National Health-care Safety Network at the Centers for Disease Control and Prevention, 2009-2010. Infect Control Hosp Epidemiol. 2013; 34:1-14.

6. Bagshaw SM, Laupland KB. Epidemiology of Intensive Care Unit - acquired Urinary Tract Infections. Current Opinion in Infectious Diseases. 2006;19:67-71.

7. Lane DR, Takhar SS. Diagnosis and Management of Urinary Tract Infection and Pyelonephritis. Emmergency Medicine Clinics of North America. 2011;29:539-52.

8. Arredondo-Garcia JL, Amabile-Cuevas CF. High Resistance Prevalence towards Ampicillin, Cotrimoxasole and Ciprofloxacillin among Uropathogenic E coli Isolates in Mexico City. J Infect Dev Citres. 2008;2:350-3.

9. Nickavar A and Sotoudeh K. Treatment and Prophylaxis in Pediatric Urinary Tract Infections. Int J Prev Med. 2011;2:4-9.

10. Michael M, Hodson EM, Craig JC, Martin S, Moyer VA. Short Compared with Standard Duration of Antibiotic Treatment for Urinary Tract Infection: A Systemic Review of Randomized Controlled Trials. Arch Dis Child. 2002;87:11823.
11. Strohmeier $\mathrm{Y}$, Hodson EM, Webstar AC, Craig JC. Antibiotics for Acute Pyelonephritis in Children. Cochrane Database of Systemic Reviews 7:CD 003772. July 2014.

12. Five Things Physician and Patients should Question- choosing wisely: an Initiative of the ABIM Foundation, American Urogynaecologic Society, retrived on june 1, 2015

13. Knottnerus BJ, Grigoryan L. Comparative Effectiveness of Antibiotics for Uncomplicated UTI: Network Meta-analysis of Randomized Trials. Family Practice Decem. 2012;29:65970.

14. Farrel DJ, Morrisey I, De Rubeis D, Robins M, Felminghan. AUnited Kingdom Multicenter Study of the Anti-microbial Susceptibility of Bacterial Pathogen causing Urinary Tract Infections. J Infect. 2003;46:94-100.

15. Kothari A, Sagor V. Antibiotic Resistance in Pathogens causing Community-acquired Urinary Tract Infections in India: a Multi-center Study. J Infect Dev Ctries. 2008;2:354-58.

16. Akram M, Shahid M, Khan A. Etiology and Antibiotic Resistance Patterns of Communityacquired Urinary Tract Infections in JNMC hospital, Aligrah, India. Ann Clin Microbiol Antimicrob. 2007;6:4.

17. Mathai E, Chandy S, Thomas K, Antoniswamy B, Joseph I, Mathai M, et al. Antimicrobial Resistance Surveillance among Commensal E coli in Rural Areas of Southern India. Trop Med Int Health. 2008;13:41-45.

18. Al Jiffiri O, Zahira MF, EL-Syed. Urinary Tract Infection and Ecoli and Antibacterial Activity of Some Plant Extract. Int J Microbiol Res. 2011; 2:1-7.

19. Willium NS, Bulstrade CJK, O'ConnellPRO, editors. $25^{\text {th }}$ ed. London: United Kingdom: Edward Arnold Publishers; 2008. Baily and Love's Short Practice of Surgery: pp 1329-30.

20. Hasan AS, Nair D, Kaur J, Baweja G, Deb M, Aggarwal P. Remission Pattern of Urinary Isolates in a Tertiary Indian Hospital. J Ayub Med Coll Abottabad. 2007;19:39-41

21. Pallett A, Hand K. Complicated Urinary Tract Infections: Practical Solutions for the Treatment 
of Multi-resistant Gram Negative Bacteria. J Antimicrob Chemother. 2010.65 Suppl 3:iii25-33.

22. Shepherd AK, Pottinger PS. Management of Urinary Tract Infections in the Era of Increasing Antimicrobial Resistance. Med Clin North Am. 2013;97:737-57.

23. Consensus Statement on Management and Audit Potential for Steroid Responsive Nephrotic Syndrome - Report of a Workshop by the British Association for Paediatric Nephrolozy and Research Unit, Royal College of Physicians. Arch Dis Child. 1994; 70:151-73.

24. Eddy AA and Symons JM. Nephrotic Syndrome in Childhood. The Lancet. 2003;362:629-36.

25. Holford NHG. Pharmacokinetics \& Pharmacodynamics: Rational Dosing \& tha Time Course of Drug Action. In: B G Katzung, editor. Basic \& Clinical Pharmacology. $9^{\text {th }}$ ed. United States: Mc Graw Hill Companies. 2004:34-50.

26. Elder JS. Urinary Tract Infection. In: Kliegman, Behrman, Jenson, Stanton, editors. Nelson Textbook of Pediatrics. 18th ed. Philadelphia: Kliegman Saunders. 2007:2223-25.

27. Dulczak S, Kirk J. Overview of the Evaluation, Diagnosis and Management of Urinary Tract Infections in Infants and Children. Urol Nurs. 2005;25:185-192.

28. Senguttuvan P, Ravanan K, Pravu N, Tamilarasi V. Infection Encountered in Childhood Nephrotics in a Paediatric Renal Unit. Indian J Nephrol. 2004;14:85-88.
29. Rahman M, Rahman KM. Urinary Tract Infection in School Children.BMRC Bulletin. 1979;2:67-70.

30. Emilia M, Dantas S, Vera H, Maria DF and Yassuhiko O. Influence of Nephrotic State on the Infectious Profile in Childhood Idiopathic Nephrotic Syndrome. Rev Hosp Clin Fac Med S Paulo. 2004;59:273-78.

31. Mazzalli T. Resistance Trends in Urinary Tract Pathogens and Impact on Management. J Urol. 2002;168:1720-22.

32. Catal F, Bavbek N, Bayrak O, Karabel D. Antimicrobial Resistance Patterns of Urinary Tract Pathogens and Rationale for Empirical Therapy in Turkish Children for the Years 2000 - 2006. Int Urol Nephrol. 2009;41:953-57.

33. Anandkumar H, Kapur I, Dayanand A. Increasing Prevalence of Antibiotic Resistance and Multidrug Resistance among Uropathogens. J Communn Dis. 2003;35:102-08.

34. Yuksel S, Ozturk B, Kavaz A, Ozcakar ZB. Antibiotic Resistance of Urinary Tract Pathogens and Evaluation of Empiric Treatment in Turkish Children with Urinary Tract Infection. Int J Antimicrob Agents. 2006;28:413-16.

35. Tseng MH, Lo WT, Lin WJ, Teng CS, Chu ML, Wang CC. Changing Trend in Antimicrobial Resistance of Pediatric Uropathogens in Taiwan. Pediatr Int. 2008;50:797-800.

36. Das Muktikesh, Padhi S, Mohanty I, Panda P, Parida B. Anti-microbial Resistance in Pathogens causing Urinary Tract Infections in a Rural Community, Odisha, India. J Family Community Med. 2013;20:20-26. 